
$\checkmark$ Research Square
Preprints are preliminary reports that have not undergone peer review.
They should not be considered conclusive, used to inform clinical practice, or referenced by the media as validated information.

\title{
Does Integrated Medical Insurance System (IMIS) Alleviate the Difficulty of Using Cross-Region Health Care for the Migrant Parents in China
}

\section{Chao Ma}

Southeast University

Shutong Huo ( $\nabla$ shutonh@uci.edu )

Yale University School of Public Health

Hao Chen

University of International Business and Economics

\section{Research}

Keywords: Integrated Medical Insurance System (IMIS), migrant parents, medical care, China

Posted Date: September 1st, 2020

DOI: https://doi.org/10.21203/rs.3.rs-45706/v1

License: () (i) This work is licensed under a Creative Commons Attribution 4.0 International License. Read Full License 


\section{Abstract \\ Background}

A large number of internal immigrants in the process of urbanization in China is Migrant Parents, the aging group who move to urban area involuntarily to support their family. They are more vulnerable economically and physically than the younger migrants. However, the fragmentation of rural and urban health insurance schemes divided by "hukou" household registration system limit migrant's access to healthcare services in their resident location. Some provinces have started to consolidate the Urban Resident Basic Medical Insurance and the New Rural Cooperative Medical Scheme as one Integrated Medical Insurance Schemes (IMIS) to reduce the disparity between different schemes and increate the health care utilization of migrants.

\section{Methods}

Using China Migrants Dynamic Survey, we used OLS for regression in models.

\section{Results}

We found that the migrant parents who are covered by the IMIS are more likely to choose inpatient service and to seek medical treatment in the migrant destination, by improving the convenience of medical expense reimbursement and relieving the economic pressure.

\section{Discussion}

The potential mechanisms of our results could be that IMIS alleviates the difficulty of seeking medical care in migrant destination by improving the convenience of medical expense reimbursement and relieving the economic constrain.

\section{Introduction}

The rapid economic growth of China has resulted in a historically unprecedented surge in urbanization. The urban population in China has more than tripled in the past three decades (Yeh et al.,2011). One of the important reasons is that increasing numbers of rural inhabitants have joined this exodus to the cities in search of better job opportunity and improved quality of life. According to the National Bureau of Statistics (National Bureau of Statistics of China,2017), there were about 121 million floating populations in 2000. This number increased to 221 million in 2010, and reached to 245 million in 2016 (accounting for $18 \%$ of the country's population), which may constitute the most massive migration in the history of humankind (Tang,2013). Another demographic characteristic of floating population in China is that more and more elderly member migrated with their families during the last two decades. The proportion of migrants aged over 45 years increased from $9.7 \%$ in 2010 to $12.9 \%$ in 2014 (National Health and Family Planning Commission,2015).

Among the large numbers of elderly immigrants, the Migrant Parents (the aging groups who move to urban area involuntarily to support their family) is more vulnerable than others. This particular group is less economically and physically able to overcome the negative effects of migration compared with younger migrants due to their physical, mental and social network features. However, the fragment health insurance system in China caused large disparity between different residency status, which means the migrant aging groups from rural area have difficulties to fully enjoy the health care in urban cities. Accordingly, the unmet health care utilization harms the Migrant Parents' well-being, as well as the health equity in Chinese society. This paper aims to discuss whether the integration of health insurance schemes could increase the health care utilization of Migrant Parents and satisfy their health need. Our results also shed light on the universal health coverage in worldwide and the merging health insurance market in the United States. Especially, we provide international evidence on how the national health insurance schemes could increase the health care utilization of the vulnerable groups.

In fact, a large proportion of rural migrants in China are usually engaged in 3D (i.e., dirty, dangerous, and demanding) work that native residents are seldom willing to perform. They often work longer hours at higher intensity than native residents do, with less protection (Meng,2012). On the contrary, the rural migrants are often systematically excluded from urban public resources, one of which is the access to healthcare (Gong et al.,2012; Hong et al.,2006). On one hand, the Urban Employee Basic Medical Insurance (hereafter UEBMI) only covers the urban workers but excludes cover informal sector workers and migrant workers (Hu et al.,2008; Ramesh and Wu,2009). On the other hand, the basic health insurance schemes used to be divided by "hukou" household registration system in China, Urban Resident Basic Medical Insurance (hereafter URBMI) for urban residents and the New Rural Cooperative Medical Scheme (hereafter NCMS) for rural residents, causing large fragmentation in the health insurance system. The identity-based schemes limit migrant's access to healthcare services in their job locations, because it is difficult for them to transfer the schemes from rural to urban area and use a specific health insurance account across schemes (Hu et al.,2008). Given that, migrants receive less coverage under formal medical schemes and they encounter more barriers when applying for reimbursement of treatment expenses (Hesketh et al.,2008; Nielsen et al. 2005). Furthermore, URBMI and NCMS have separate administrative institutions mechanisms and different financing pooling level, which leads to low risk protection ability and poor interconnections within the health insurance system, thereby causing significant inequity issues for migrants (Shan et al. 2018; Wang et al.,2012). NCMS funds are pooled at the county level, while URBMI and UEBMI are pooled at the municipal (prefecture) level, which implies that in China there are thousands of health insurance schemes. In this way, the reimbursement levels and benefit packages differ among schemes in different districts due to the disparity of economic development, which causes large inequality in health care utilization between different schemes (Fu et al.,2014; Meng et al.,2015).

As the fragmentation of rural and urban health insurance schemes has been recognized as one of the most important factors determining the disparities in social and economic development in China (Ministry of Health,2012), some provinces started to consolidate the NCMS and URBMIS as one Integrated Medical 
Insurance Schemes (hereafter IMIS). The consolidation aims to raise the insurance pooling level, simplify the reimbursement process cross regions and equalize the benefit package and risk protection ability among all groups of people (Pan et al.,2016).

Pushed even further, there are several reasons for us to care more about the consequence of IMIS on the Migrant Parents population. Although migrant workers face a higher risk of poor health and lower chances of accessing and affording treatment in cities, indeed, most studies found that migrants exhibit better health than natives do because young and healthy individuals having a higher propensity to migrate (Halliday and Kimmitt,2008; McDonald and Kennedy,2004; Rubalcava et al.,2008). Also, serious and incapacitating diseases and intensive-care conditions can result in a migrant's return home to avoid the high medical and living costs in cities (Bai and He,2002; Fong 2008; Zhang et al.,2007). This phenomenon is called health immigrants effect (HIE), which cause the limited access to healthcare in their new place of residence is not a serious problem for the younger migrants in China (Chen,2011; Fong 2008; Lu,2008; Lu and Qin,2014). Nevertheless, the Migrant Parents are less likely to be adopted by HIE phenomenon when migrant to urban area, because many Migrant Parents involuntarily. Instead of searching for job opportunities as young people do, the Migrant Parents group makes the decision based on family factor, like looking after their grandchildren (Dou and Liu,2017). Thus, the Migrant Parents group is more vulnerable than the young migrants to be affected by the inconvenience of reaching medical need. Therefore, the integration of NCMS and URBMIS should benefit the Migrant Parents even more by increasing access to health care in their migrate destinations.

In addition, that the Migrant Parents do have higher prevalence and incidence of many diseases, especially chronic diseases, and need more health care services than the younger population due to the decline of resistance and physical function because of their aging (A Randomized Trial of Intensive versus Standard Blood-Pressure Control,2015; Older Americans,2016: Key Indicators of Well-Being n.d.; Gorina et al.,2005; Group,2012; Siu and US Preventive Services Task Force,2016; Wang and Martin,2012). Moreover, the Migrant Parents need to acculturate to a new environment and leave a familiar culture behind (Mjelde and Lou,2006; Zhao,1999). The elders who used to live in villages lost their daily work, lifestyle and community networks when their change residence from rural to urban (Li et al.,2017). This changing social environment has been linked to elder depression (Wu et al,2004; Dong et al.,2012; Shen and Takeuchi,2001; Wang and Zhao,2012).

In consequence, what we investigate in this study is of great importance both in reality and in the literature. Using China Migrants Dynamic Survey, we found that the migrant parents who are covered by the IMIS are more likely to choose inpatient service and to seek medical treatment in the migrant destination, by improving the convenience of medical expense reimbursement and relieving the economic pressure. The potential mechanisms could be that IMIS alleviates the difficulty of seeking medical care in migrant destination by improving the convenience of medical expense reimbursement and relieving the economic constrain. The remainder of the paper is organized as follows. We review some of the related empirical literature. Next, we describe the data and measurements, and lays out the analytic strategy. Then we present our main findings. Finally, we discuss the implication of our results, the limitations of our work, and potential future directions.

\section{Background}

\section{Health and Health Care Utilization of the Elderly in China}

Illness increases with age, like cardiovascular disease, hypertension, cancer, osteoarthritis and et al.(A Randomized Trial of Intensive versus Standard BloodPressure Control,2015; Older Americans,2016: Key Indicators of Well-Being n.d.; Gorina et al.,2005; Group,2012; Siu and US Preventive Services Task Force,2016; Wang and Martin,2012). The same as in China, the health of the elderly worsens with age, suffering from both cognitive and physical health issue (Smith et al,2014). In the case of China, the urban-rural dualistic structure has created a dual lifestyle and cultural belief (Li et al.,2017). As older people move, they face drastic change on lifestyle and living environment, which have been reported by World Health Organization as main factors affecting health. As a result, the older people, especially the migrant parents, have a greater needs for health care (Butler,1997; Evans et al.,2001; Schneider and Guralnik,1990).

One of the most effective way to satisfy the health care utilization among the elderly who need the services is cover them the health insurance. A large body of literature show that health insurance coverage can sharply increase the health care utilization among elders(Andersen,2018; Card et al,2008; McWilliams et al.,2003). A study based on Medicare in the U.S. reveals that the universal insurance coverage increases the use of health care utilization among the elders(Card et al,2008). Taiwan's National Health Insurance coverage also has significantly increased utilization of both outpatient and inpatient care among the elderly, and such effects were more salient for people in the low or middle income groups(Chen et al.,2007).

In terms of China, the increases in health insurance coverage were accompanied by increased use of health care among the elderly(Li et al.,2019). The URBMI program has significantly increased the utilization of formal medical services, improving even more for the elderly(Liu and Zhao,2012). It also has been shown that NCMS has improved the health care utilization of rural elders(Dai et al.,2011; Liang and Lu,2014). However, URBMI have greater impact than other insurance policies since it receives more government finance than other schemes (Liu and Wong,2016). Liu and Wong (2016) found that the recruitment of URBMI increases the health care utilization, but signing up for NCMS does not improve both the utilization and health outcome among the elders. However, there are rare researches focusing on how IMIS influence the health care utilizations among elders.

\section{Health Care Utilization of the Migrants}

The migrant workers have made a tremendous contribution to China's economic development. However, migrants face barriers to access to health care. Gong et al. (2012) suggested that migrant workers consistently underused health services both at their hometowns with hukou and at residences (Gong et al.,2012). In fact, rural-to-urban migrants always are excluded from city health systems, because they cannot qualify for the UEBMI and URBMI as local city residents can, even when they are working in the same company and living in the same community (Dong and Bowles,2002). Even the employed floating population in urban areas supposed to be covered by health insurance provided by their employers under UEBMI, employers usually lack motivation or pressure to do so (Liu 
and Zhao,2012). As a result, they can only participate in their local NCMS, which in turn poses barriers when migrants seek health care in their destination cities.

Many complaints have been made because of the poor portability of the schemes across locations, unsatisfactory transferability across the schemes and weak interconnections among and within the schemes(Shan et al.,2018). Specifically, seeking hospital care in out-of-county hospitals resulted in a much lower reimbursement rates or even no reimbursement from the NCMS (Qiu et al.,2011), which might leads their lower health care utilization than they actually need. A cross-sectional study in 2005 in Shenzhen, a large city hosting a significant number of migrant workers, showed that $55 \%$ of the migrant workers were uninsured, and $62 \%$ of those who reported illness did not seek professional care(Mou et al.,2009). In terms of the aging groups in migrants, according to the 2015 China Migrants Dynamic Survey (CMDS), 54.27\% of the elderly migrants preferred being either self-treated or untreated rather than visiting hospitals; $18 \%$ requiring hospitalization did not use the inpatient service, and among those who received it, $30 \%$ returned to their hometown for hospitalization(Wang,2017).

\section{Chinese Basic Health Insurance System and the Integrated Medical Insurance Schemes}

China has spent a long period of time for health insurance reform and successfully achieved universal health insurance coverage in 2011 , by which $95 \%$ of Chinese population was insured compared with less than 50\% in 2005(Liang and Langenbrunner,2013). The coverage was offered through three public insurance programs, New Rural Cooperative Medical Scheme (NCMS), Urban Resident Basic Medical Insurance (URBMI) and Urban Employee Basic Medical Insurance (UEBMI). In 2003, China launched NCMS, a greatly subsidized voluntary health insurance program for rural residents. It serves as a replacement for the old village-based rural health insurance program. Most rural-urban migrants were enrolled in the NCMS due to their residency. On the other hand, URBMI started in July 2007, providing coverage for the urban residents without formal jobs or unemployed such as children, students, elderly, and the young unemployed. While NCMS and URBMI cover most of the residents in rural and residents without job in urban, UEBMI aims to provide health insurance to employed urban residents. Based on the pilot reforms in the cities of Zhenjiang and Jiujiang, UEBMI was proposed to replace the government insurance scheme and the labor insurance scheme(Liu,2002; Xu et al.,2007). In general, UEBMI stipulates that the employment-based basic health insurance scheme should cover urban employees, including workers from both public and private enterprises. Retired workers are exempted from premium contributions, and their former employers should shoulder the costs of their contributions. It means that the elder migrants who did not retired in urban area are not beneficiaries of UEBMI as well.

Nevertheless, the practice of applying three schemes to different crowd with different administration and financial pools has resulted in a fragmented health insurance system. For instance, NCMS is pooled at county level for rural residents (2852 rural counties in 2012), while UEBMI and URBMI are pooled at municipal level for urban individuals (333 municipalities and prefectures in 2012). The large number of schemes cause cumbersome management and impaired efficiency, as well as the inequality of benefit packages and risk protection. Firstly, a wide gap in benefit levels is observed cross different schemes. The NCMS had lower reimbursement rate and smaller services coverage than UEBMI and URBMI (Fu et al.,2014; Yang and Wu,2015). Secondly, the fact that NCMS funds are pooled by counties has affected risk sharing between counties with different financial status (Meng et al.,2015). For example, some eastern and coastal region can expand the benefit package by its own government and offer more comprehensive coverage to their residents. On contract, the poorer the county has the lower level of financial pooling, which weakened the ability of health insurance funds (Barber and Yao,2011; Lei and Lin,2009). In addition, NCMS is operated by the Chinese National Health and Family Planning Commission (previously the Chinese Ministry of Health), whereas URBMI and UEBMI are administered by the Chinese Ministry of Human Resources and Social Security. The competition between two departments in their attempts to seize more administrative power caused resource wasting and low efficiency (Shan et al.,2018).

The fragmentation of rural and urban health insurance system had been characterized as a factor determining the disparities in social and economic development in China (Ministry of Health,2012). As a result, the integration of NCMS and URBMI was an urgent need. Beginning from 2008, some province and cities started practice the consolidation of two residential insurance schemes. However, due to the absence of institutional design and guidelines from the national government, the reform in pilot area were not sufficient (Hu et al,2014; Yang and Liu,2014; Zheng,2014).

To move forward to the thorough reform, in 2015, the leader in China announced the decision to merge the NCMS and URBMI. In January, 2016, China officially issued a document on integrating NCMS and URBMI regarding insurance coverage, funding policies, insured treatment, reimbursement catalogues, management of contracted medical institutions and fund management, which is called Integrated Medical Insurance Schemes (IMIS) (The General Office of the State Council of China,2016). Aiming to break the limitation of fragmented administration, the National Healthcare Security Administration was launched in March 2018, which oversees and manage the health insurance plan, drug price and purchase, medical aid and maternity insurance at national level (The State Council,2018).

At this point, 24 provinces have integrated the NCMS and URBMI and operated the IMIS. A document from the National Healthcare Security Administration has emphasized that the rest 7 provinces should increase the speed of consolidating schemes process(National Healthcare Security Administration,2019).

\section{Data, Variable And Descriptive Statistics}

\section{Data}

We use 2015 China Migrants Dynamic Survey (CMDS) in this study, conducted by the National Population and Family Planning Commission. The survey covers all 32 provinces of China, 348 cities and 10300 communities or villages. The 2015 CMDS adopted a stratified three-stage probability proportionate to size (PPS) sampling, and the annual national data on migrants from each province in 2014 was considered the basic sampling frame. In each selected community, 20 eligible individual migrants were randomly selected to participate in the survey. The migrant participants of the household survey are those 
who are between 16 and 59 years old and have moved across a county boundary from their registered household and have been living in a city for more than 1 month. The sample is representative at the national and provincial levels.

\section{Variable}

To examine the relationship between health care utilization and the IMIS policy, we use the following model:

$$
H C_{i j}=\text { Bimis }_{i j}+\gamma \text { need_inpa } i j+\varnothing X_{i j}+\text { region }_{j}+\varepsilon_{i j} \quad(1)
$$

Where $H C_{i j}$ is our dependent variable, health care utilization of individual $i$ in region $j$. The key independent variable in this study was ${ }^{i m i s_{i j}}$ (whether the individual participated in IMIS), it equals 1 if the person participates in IMIS and 0 if otherwise. need_inpa $a_{i j}$ denotes people have had an illness/injury diagnosed by doctors in the past year that requires hospitalization. This model also includes a set of control variables $X_{i j}$. region $_{j}$ represents the fixed effects of the origin provinces as well as the flow-in cities. $\varepsilon_{i j}$ is the error term.

There are two main indexes in this study: inpa (whether hospitalized in the past year) and local_inpa (whether hospitalized locally in the past year). If a doctor determines that the patient needs to be hospitalized, whether patients choose to be hospitalized and whether they choose to be hospitalized locally is a good indicator of the accessibility of medical services. Specifically, if we control the variable need_inpa which can reflect the needs of hospitalization, inpa can effectively represent proper health care or not has been received by people, and it is useful for us to investigate the impact of integrated medical insurance system (IMIS) on alleviating the difficulty of Migrants Parents (parents who are driven to follow their children to other cities) to seek medical treatment. The other variable local_inpa can effectively identify whether an individual is enjoying local medical resources, or not treating the sick locally just like going back home for treatment ${ }^{[1]}$. We also have another dependent variable less_serious_doctor(whether people will see the doctor locally if they get a less serious disease) for reference only, which reflects whether Migrants Parents have a problem with excessive medical care.

Specifically, the series of controlling variables $X_{i j}$ include: household incomes per capita, household expenditure per capita, household expenditure on food per capita, household expenditure on house per capita, hukou status, education level, and principal source of income are used to evaluate the socialeconomic status (SES) of the individuals. Self-reported health status, whether diagnosed with diabetes or hypertension, and whether has the impatient need are used as the health status indicators. We controlled for the fitness time per week and whether has the medical examination this year as the proxy of the health behavior variables. Additionally, gender, age, ethnic, and marital status were also controlled for as the demographic variables. Finally, we added the number of friends in the flow-in cities, years since migration (YSM), and the main reason of migration as the proxy of the migration status. Table 1 reports descriptive statistics for the main variables.

\section{Descriptive Statistics}

The descriptive statistics in Table 1 can partially explain the issues concerned in this paper. By comparing Migrants Parents who have already joined IMIS (we define them as IMISs) and who have not (non-IMISs), we find that when the mean value of need_inpa was almost the same (0.108 and 0.098$)$, the mean value of IMISs on local_inpa was much higher than that of non-IMISs ( 0.081 and 0.058$)$. This means that when Migrants Parents are deemed to be in hospital by the doctor, IMISs will choose to be in hospital locally and enjoy local medical services instead of those in hometown. The reason why we emphasize the mean value of need_inpa is almost the same is that the proportion of Migrants Parents who need to be hospitalized due to illness must be guaranteed to be similar, so it is meaningful to compare the proportion of local hospitalization of IMISs and Non-IMISs, which can reflect the improvement in the utilization efficiency of local medical services with the aid of IMIS. In addition, there is also a difference in inpa between IMISs and Non-IMISs (0.096 and 0.080$)$, which proves that if hospitalization is indeed required, IMISs will be less likely to "not go to treatment for illness".

Other variables also show interesting patterns. We find that IMISs have higher SES than non-IMISs, including higher education (2.312 and 2.135$)$, more nonagricultural hukou (0.569 and 0.852), higher monthly household income per capita $(2,091.701$ and 1,918.866) and expenditure per capita $(1,109.474$ and 959.597). Also, we find IMISs have more local friends (8.562 and 7.486), more adequate exercise time (73.432 and 62.302) and more regular physical examination ( 0.447 and 0.315$)$. These statistical results have two meanings: on the one hand, it indicates that there are many factors influencing the results, which need to be controlled in the following regression. On the other hand, it implies a possible risk of selection bias. For example, those IMISs who seem to be more locally hospitalized and hospitalized have higher SES, instead of that IMIS is the main reason why they chose to be inpatient service locally. In other word, it is possible that the area that implements IMIS might have better economics status than those without IMIS. In order to eliminate this doubt, non-IMISs are further divided into NCMSs (Migrants Parents who only participates in the New Rural Cooperative Medical System) and URBMIs (Migrants Parents who only participates in the Urban Residents Basic Medical Insurance). Because it can be seen that although SES of IMISs is significantly higher than that of NCMSs, it is not completely higher than that of URBMIs. IMISs are even lower than URBMIs in years of education, marital status, monthly household income and expenditure per capita, number of local friends and average daily exercise time. Even so, IMISs was still higher than URBMIs in the mean value of the two dependent variables, and it can be seen that selection bias has little influence on the results. Higher SES cannot fully explain the improvement in the efficiency of enjoying local medical resources, which means that Migrants Parents who need to be hospitalized choose to go to hospital and stay in local hospitals more often should be attributed to IMIS policy.

\section{Empirical Results}

\section{Baseline Results}


Tables 2 reports the baseline results, whose dependent variables are inpa, local_inpa and less_serious_doctor. Columns (1) - (3) of table 2 focus on IMISs vs. Non-IMISs, columns (4) - (6) focus on IMISs vs. NCMSs, and columns (7) - (9) focus on IMISs vs. URBMIs. Columns (1), (4) and (7) control the health status, health behaviors, individual demographic characteristics and city fixed effect besides imis. Columns (2), (5) and (8) also control SES and immigration information on the basis of (1), (4) and (7). Columns (3), (6) and (9) also control need_inpa on the basis of (2), (5) and (8). Table 3 has the same structure as table 2. The regression results in table 4 are for reference only, because the dependent variable is not an established fact but a subjective attitude, Migrants Parents' willingness to seek medical treatment locally even if they are just a little ill. At the same time, we realize that the effect of IMIS is less obvious compared with severe diseases requiring hospitalization, which is shown in the weaker coefficient of imis in table 4. This is also intuitive: for minor illness, the requirements for reimbursement, price and medical convenience are lower. Many Migrants Parents are still willing to go to local hospitals even without medical insurance.

We need to focus on explaining the regression results in table 2 and table 3 . First of all, in column (1) - (6) of table 2 and table 3 , the coefficient of imis is positive, showing that compared with Non-IMISs or NCMSs, migrant parents who are in IMIS enjoy more local medical services. Especially the coefficient of imis is significantly positive in column (3) and (6), which shows that it is significantly easier for IMISs to be hospitalized in local hospitals when they are sick and needs to be hospitalized. It should be noted that in the column (7) - (9) of regression comparing IMISs and URBMIs, the coefficient of imis is still significantly positive in most cases, but the significance level has decreased. This may be due to the small sample size of URBMIs, so it does not affect the establishment of the conclusions in this paper. Further comparison between table 2 and table 3 shows that when the dependent variable is local_inpa, the coefficient of imis is more significant and larger, indicating that IMIS makes Migrants Parents more willing to stay in local hospitals when they need to, instead of going back to their hometown for hospitalization. This also reflects the medical convenience IMIS brings to migrant parents. This also reflects the medical convenience which IMIS brings to migrant parents.

In addition, we do not worry too much about endogenous even if we only use OLS for cross section data. On the one hand, the self-selection mentioned above will be alleviated by further subdivision. On the other hand, Basic medical insurance in China is fixed on individuals by their hukou and local medical insurance policies, so there is little adverse selection of medical insurance by individuals. Moreover, the migration of migrant parents is often passive (they follow their children to migrant), so there is almost no self-selection bias for Migrants Parents. In summary, OLS results based on cross section data in our research are reliable.

\section{Robustness Check}

\section{Selection Bias Problem of IMIS Policy}

We further subdivide Non-IMISs into NCMSs and URBMIs in the regression to alleviate the doubt about endogenous. As we mentioned above, there is a significant disparity between NCMSs and URBMIs on SES, while the mean value of SES of IMISs is just between them. We compare IMISs with URBMIs in table 3 and with NCMSs in table 4 separately, the results reveal that the migrant parents in IMIS use more local medical services than both of them in URBMI and NCMS. Therefore, we don't need to worry that the positive influence of IMIS on the dependent variable comes from the self-selection of SES dominant group (URBMIs).

\section{Adjust for possible IMIS misinformation and distortion}

In our data used in this paper, there are 1029 URBMIs, among which 263 (25.56\%) are rural residents with agriculture hukou. According to the policy in China, rural residents with agriculture hukou can only participate in NCMS, so it appears a paradox. The most likely fact is that these people are actually IMISs, but misreport or join insurance types repeatedly. First, in most regions, IMIS is a process which is promoted from NCMS with lower reimbursement treatment to URBMI with higher reimbursement treatment. For rural elderly, it is also a process of realizing the treatment of urban residents, making them mistakenly believe that they have become URBMIs. Second, in China, NCMS is usually administrated by the local health department, while URBMI is usually administrated by the local human resources and social security department. When NCMS and URBMI are merged into IMIS, IMIS will be administrated by the local human resources and social security department. In this way, it is easy for Migrants Parents with agricultural hukou to mistake themselves for URBMIs. Third, the difference between URBMI and IMIS is only one character in Mandarin Chinese. Migrants Parents with agricultural hukou often have a low level of education. It is possible to mistake URBMI for IMIS when they answer questions in the questionnaire.

As a result, we conduct a robustness check in which the 263 samples are regarded as IMISs, and the results are shown in table 5 . In addition, we adjusted the repeated insurance enrollment in table 6 . Columns 1-3 in table 5 and 6 are equivalent to columns 3,6 and 8 in table 2. Columns 4-6 in table 5 and 6 are equivalent to columns 3,6 and 8 in table 3 . Columns $7-9$ in table 5 and 6 are equivalent to columns 3,6 , and 8 in table 4 . It can be seen that after the adjustment for the possible data deviation, the conclusion has not changed.

\section{Self-selection on hukou}

As mentioned above, what kind of medical insurance residents enjoy depends on local policies and their hukou in China, therefore self-selection on IMIS does not exist. However, self-selection on hukou still exists. In general, those who are able to convert their or their families' hukou from agricultural to nonagricultural have higher SES. For this reason, we repeat the previous baseline regression process after dropping the individuals who have changed the nature of hukou (from agricultural to non-agricultural). The results are shown in table 7, and the conclusion still has not change. In fact, only $1.5 \%$ of Migrants Parents changed the nature of their hukou (from agricultural to non-agricultural) among the respondents in our data.

\section{Exclude samples whose reason for migration is seeking medical treatment}


As previously stated, Migrants Parents usually migrate "passively" because they move for their children, so there is little serious self-selection on mobility. However, if the reason for the old people to migration is to seek medical treatment, they will choose the place where it is easy to get medical treatment, which will result in serious self-selection on mobility and thus cause the confusion of regression conclusion. Fortunately, only $0.86 \%$ of Migrants Parents moved for medical treatment. After removing this part of samples, the previous regression process is repeated and the results are shown in table 8 . There is no difference between the results and baseline results.

\section{Exclude samples whose YSM is less than one.}

As we mentioned, positive self-selection of migrants posits that only the healthiest and most motivated individuals choose to move to a new place, while less healthy and weaker individuals stay behind. Considering the Migrant Parents might be healthier than the native population when they first arrive the host cities, we dropped the samples who has YSM less than 1 and repeated previous regression. The results shown in table 9 reveals that there is no difference between the results and baseline results.

\section{Potential Mechanisms}

To investigate the mechanisms of IMIS relieving the difficulty of medical treatment in migrant destination, we should discuss the reason for IMIS improving the willingness of the Migrants Parents to be hospitalized in the destination. In this paper, we can only preliminarily investigate the reasons for IMIS improving hospitalization intention and give our suggestive evidence through simple descriptive statistics because of limited observations.

In the samples used in this paper, there are 146 people who got illness which doctors thought required hospitalization, but they give up. 10 of them are IMISs, and 136 are Non-IMISs. This, of course, once again proves that IMIS has greatly reduced the possibility of Migrants Parents being sick but not going to treatment. For those responders who did not to be hospitalized, the questionnaire further inquired the reasons why they choose not to be hospitalized. The statistical results are shown in table 8 . There are two important results: first, 15 people $(11.03 \%)$ in the Non-IMISs group chose not to be hospitalized because of "inconvenient reimbursement", while 0 people complained about "inconvenient reimbursement" in the IMISs group. It indicates that IMIS has improved the willingness to be hospitalized in the migrant destination, probably because IMIS has improved the convenience of medical expense reimbursement. Second, 38 people (27.94\%) in Non-IMISs chose not to be hospitalized because of "poor", while only 1 person (10\%) in IMISs chose "poor", which indicates that another mechanism for IMIS to improve the intention of hospitalization in the destination is to relieve the economic constrain caused by medical expenses. Based on the above discussion, it can be concluded that IMIS can alleviate the difficulty of seeking medical care in migrant destination mainly through two ways: improving the convenience of medical expense reimbursement and relieving the economic constrain. Fortunately, both improving the convenience of medical expense reimbursement and relieving the economic constrain are goals and original intentions of IMIS.

\section{Conclusion And Discussion}

This paper discusses the influence of IMIS in China on the difficulty of migrant parents to seek medical treatment in migrant destination. We find that IMIS indeed alleviates the difficulty of aging Migrants Parents in seeking medical treatment in migrant destination. It can be reflected from the fact that IMISs are more likely to choose hospitalization and to seek medical treatment in the migrant destination than Non-IMISs. In order to reduce the possible interference of selection bias on the conclusion, we further subdivide Non-IMISs into NCMSs and URBMIs, which are respectively compared with IMISs. It has proved that the conclusion of IMIS alleviating the difficulty of getting medical treatment in migrant destination still remains.

Our paper attempts to further discuss the channels of IMIS easing medical treatment difficulty in migrant destination. The result gives us good inspiration: IMIS can alleviate the difficulty of seeking medical care in migrant destination mainly through two ways: improving the convenience of medical expense reimbursement and relieving the economic constrain. Therefore, it has been found in the survey that compared with Non-IMISs, almost no IMISs give up hospitalization in migrant destination because of inconvenient reimbursement and economic constrain. Before piloting the IMIS, most NCMS schemes require prior approval for the use of services in non-local facilities, and the process tends to be rather lengthy, thus creating an additional barrier for the Migrants Parents to use health care services locally (He and Wu,2017; Q. Meng and Xu,2014; Wang et al.,2012). In this case, even though out-of-county bills were covered by some NCMS schemes, the reimbursement ratio tends to be lower while outpatient costs are typically non-reimbursable (Qiu et al.,2011).

What we investigate in this study is of great policy implication. This paper provides empirical evidence for China's adherence to the IMIS reform direction. Even China has successfully accomplished a high health insurance coverage rate, 99.36\% (Commission,2017), the vulnerable groups such as older migrant are still in the disadvantage position in terms of the limited access to health care and insufficient health care utilization. Relative to the WHO 2010 World Health Report, it is proposed that a country moving towards universal coverage should consider three dimensions: the population (who is covered), the services (which services are included), and the costs (proportion of the costs that is covered). China's IMIS reform has effectively promoted the equity of services packages and healthcare cost between groups. Although IMIS reform involves many aspects of the interests' redistribution, in which many parts of medical departments may need to pay much costs, it is worthwhile to pay such a price from the conclusion of this study. IMIS can ensure that when Migrants Parents need to be hospitalized, they will accept hospitalization and choose to go to the hospital for medical treatment in migrant destination. They will no longer give up hospitalization or go back to their hometown for medical treatment because of the complicated reimbursement procedures.

Our study of IMIS also sheds light on achieving universal health coverage and healthcare reform for the world. As China has already accomplished the universal health coverage in the population dimension, the process of building IMIS is aiming to expand the services package and enhance financial protection ability for everyone health insurance beneficiaries at a higher level. This is consistent with the United Nations sustainable development goals in 2016, which committed countries to achieve universal health coverage by 2030 with a focus on essential health services and financial protection (United Nations,2016). Our results are consistent with the researches in other country that built the integrated health insurance system, especially those with large population disparity in terms of social economic status as China. In Ghana, Kenya and Thailand, the national health insurance schemes could increase the 
health care utilization of poor and vulnerable groups(Chuma and Okungu,2011; Gobah and Liang,2011; Limwattananon et al,2007). In terms of the United States, the country with highest health expenditure in the world, the fragmentation of the healthcare system causes complicated insurance relationships, inadequate preventive care and high administrative cost. The financing of different healthcare sectors in the United States is distributed across a variety of distinct and often competing entities, each with its own objectives, obligations, and capabilities, which also affect the efficiency and the quality of health care (Cebul et al.,2008). Prior researches based on the US insurance marketplace suggests that concentration and utilization are positively related(Bates and Santerre,2008;Hanson,2019; McKellar et al.,2014), which is consistent. In addition, some researches show that the concentration of insurance companies do negotiate lower hospital prices (Dauda,2018; Ho and Lee,2017; McKellar et al.,2014). As insurers consolidate, hospitals may increasingly view quality as a means to maintain bargaining leverage in their negotiations (Hanson et al,2019).

Several limitations of this study must be noted. First, the conclusions of our study are primarily descriptive and illustrative and do not represent canonical causal effects. Secondly, due to data limitation, especially the small sample of responders whose doctors think need hospitalization does not choose hospitalization, it is impossible to carry out more detailed empirical analysis. But discussion of the work to give us suggestive evidence is more confined to the descriptive statistical analysis. Those limitations motive us to address these shortcomings in our future research.

\section{Abbreviations}

IMIS

Integrated Medical Insurance System.

NCMS

New Rural Cooperative Medical Scheme

URBMI

Urban Resident Basic Medical Insurance

UEBMI

Urban Employee Basic Medical Insurance

CMDS

China Migrants Dynamic Survey

\section{Declarations}

Ethics approval and consent to participate: Not applicable - All analyses are based on publicly available data from national surveys.

Consent for publication: Not applicable.

Availability of data and material: The datasets used during the current study are publicly available.

Competing interests: The author declares that he has no competing interests.

Funding: National Natural Science Foundation of China

Authors' contributions: CM conceptualized the study; SH (majority) and HC wrote the manuscript; HC.

Acknowledgements: The author thanks Prof. Xi Chen for his comments on this work.

\section{References}

A randomized trial of intensive versus standard Blood-Pressure control. (2015). The New England Journal of Medicine 373: 2103-16.

Andersen $₫$ MS. 2018. Effects of medicare coverage for the chronically ill on health insurance, utilization, and mortality: evidence from coverage expansions affecting people with end-stage renal disease. Journal of Health Economics 60: 75-89.

Bai NS囚He YP. 2002. Return or go out? studies on return migration of rural laborer in Anhui and Sichuan. Soc Res 3: 6478.

Barber SLXYao L. 2011. Development and status of health insurance systems in China. The International Journal of Health Planning and Management 26: 339-56.

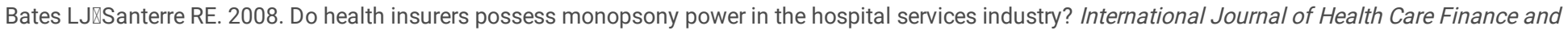
Economics 8: 1-11.

British Medical Journal Publishing. (2012). Health and disease in 85 Year olds: baseline findings from the newcastle 85+ cohort study. BMJ 345 : e4462.

ButlerヌRobert N. 1997. Population aging and health. BMJ 315: 1082-84.

Card D $\triangle$ Dobkin C $₫$ Maestas N. 2008. The impact of nearly universal insurance coverage on health care utilization: evidence from medicare. The American Economic Review 98: 2242-58. 
Cebul RD囚Rebitzer JB囚Taylor LJ et al. 2008. Organizational fragmentation and care quality in the U.S. healthcare system. Journal of Economic Perspectives 22: $93-113$.

Chen J. 2011. Internal migration and health: re-examining the healthy migrant phenomenon in China. Social Science \& Medicine (1982) 72: $1294-1301$.

Chen L $₫$ Yip WखChang MC et al. 2007. The Effects of Taiwan's National Health Insurance on Access and health status of the elderly. Health Economics 16: 223-42.

Chuma J $₫$ Okungu V. 2011. Viewing the kenyan health system through an equity lens: implications for universal coverage. International Journal for Equity in Health 10: 22

Commission $₫$ National Health囚Family Planning. (2017). China health and family planning statistical yearbook 2017. Peking Union Medical College Press Beijing.

Dai B囚Zhou J $₫$ Mei YJ et al. 2011. Can the new cooperative medical scheme promote rural elders' access to health-care services? Geriatrics \& Gerontology International 11: 239-45.

Dauda囚Seidu. 2018. Hospital and health insurance markets concentration and inpatient hospital transaction prices in the U.S. health care market. Health Services Research 53: 1203-26.

Dong XY『Bowles P. 2002. Segmentation and discrimination in china's emerging industrial labor market. China Economic Review 13: $170-96$.

Dong X『Chang ES $₫$ Wong E et al. 2012. The perceptions, social determinants, and negative health outcomes associated with depressive symptoms among U.S. chinese older adults. The Gerontologist 52: 650-63.

Dou X囚Liu Y. 2017. Elderly migration in China: Types, patterns, and determinants. Journal of Applied Gerontology 36: 751-71.

Evans RG区Mcgrail KMヌMorgan SG et al. 2001. APOCALYPSE NO: Population aging and the future of health care systems. Canadian Journal on Aging / La Revue canadienne du vieillissement 20: 160-91.

Fong VL. 2008. The other side of the healthy immigrant paradox: chinese sojourners in Ireland and Britain who return to China due to personal and familial health crises. Culture, Medicine, and Psychiatry 32: 627.

Fu R Wang Y $₫ B a o ~ H$ et al. (2014). Trend of urban-rural disparities in hospital admissions and medical expenditure in China from 2003 to 2011. PLOS ONE 9: e108571.

Gobah FF『Liang Z. 2011. The national health insurance scheme in Ghana: prospects and challenges: a cross-sectional evidence. Global Journal of Health Science 3: 90.

Gong P『Liang S『Carlton EJ et al. 2012. Urbanisation and health in China. Lancet 379: 843-52.

Gorina Y凶Hoyert D囚Lentzner $\mathrm{H}$ et al. 2005. Trends in causes of death among older persons in the United States. Aging Trends 6: 1-12.

Halliday TJ囚Kimmitt MC. 2008. Selective migration and health in the USA, 1984-93. Population Studies 62: 321-34.

Hanson C凶Herring B囚Trish E. 2019. Do health insurance and hospital market concentration influence hospital patients' experience of care? Health Services Research 54: 805-15.

Hanson CS. (2019). The relationship between insurance market concentration and healthcare use and quality: an exploration of the role of market dynamics, patient demand, and physician incentives. Thesis. Johns Hopkins University. http://dspace-prod.mse.jhu.edu:8080/handle/1774.2/61590 (August 27, 2019).

He AJ\&Wu S. 2017. Towards universal health coverage via social health insurance in China: systemic fragmentation, reform imperatives, and policy alternatives. Applied Health Economics and Health Policy 15: 707-16.

Hesketh T\Jun YX囚Lu L et al. 2008. Health status and access to health care of migrant workers in China. Public Health Reports (Washington, D.C.: 1974) 123: 189-97.

Ho K囚Lee RS. 2017. Insurer competition in health care markets. Econometrica 85: 379-417.

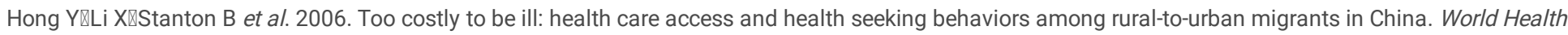
\& Population 8: 22-34.

Hu D $₫ Y e$ Y $₫$ Zhou C. 2014. The results and thinking on the integration of urban-rural medical care insurance in Taizhou. China Health Insurance (in Chinese) 5: 32-34.

Hu S®Tang S\&Liu Y et al. 2008. Reform of how health care is paid for in China: Challenges and Opportunities. The Lancet 372: 1846-53.

Hu X『Cook S『Salazar MA. 2008. Internal migration and health in China. The Lancet 372: 1717-19.

Page 9/18 
Lei X囚Lin W. 2009. The new cooperative medical scheme in rural China: does more coverage mean more service and better health? Health Economics 18: S25-46.

Li J囚Shi L囚Liang H et al. 2019. Health care utilization and affordability among older people following China's 2009 health reform - evidence from Charls pilot study. International Journal for Equity in Health 18: 62.

Liang L囚Langenbrunner JC. (2013). The long march to universal coverage: lessons from China. http://agris.fao.org/agris-search/search.do? recordID=US2014601448 (August 17, 2019).

Liang Y \&Lu P. 2014. Medical insurance policy organized by chinese government and the health inequity of the elderly: longitudinal comparison based on effect of new cooperative medical scheme on health of rural elderly in 22 provinces and cities. International Journal for Equity in Health 13: 37.

Li Q®Zhou X囚Sha et al. 2017. The effect of migration on social capital and depression among older adults in China. social psychiatry and psychiatric epidemiology 52: 1513-22.

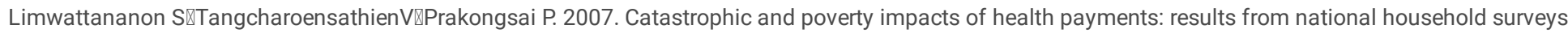
in Thailand. Bulletin of the World Health Organization 85: 600-606.

Liu HखZhao Z. (2012). Impact of China's urban resident basic medical insurance on health care utilization and expenditure. rochester, NY: social science research network. SSRN Scholarly Paper. https://papers.ssrn.com/abstract=2157910 (August 17, 2019).

Liu X囚Wong H. 2016. The reform of the medical welfare system and health equity for the elderly in China: A study in Zhejiang. The Journal of Chinese Sociology 3: 6.

Liu Y. 2002. Reforming China's urban health insurance system. Health Policy (Amsterdam, Netherlands) 60: 133-50.

Lu Y. 2008. Test of the 'Healthy Migrant Hypothesis': A longitudinal analysis of health selectivity of internal migration in indonesia. Social Science \& Medicine 67: 1331-39.

Lu Y『Qin L. 2014. Healthy migrant and salmon bias hypotheses: A study of health and internal migration in China. Social Science \& Medicine $102: 41-48$.

McDonald JT『Kennedy S. 2004. Insights into the 'healthy immigrant effect': health status and health service use of immigrants to Canada. Social Science \& Medicine (1982) 59: 1613-27.

McKellar MR囚Chernew M®Chandra A et al. 2014. Insurer market structure and variation in commercial health care spending. Health Services Research 49: 878-92.

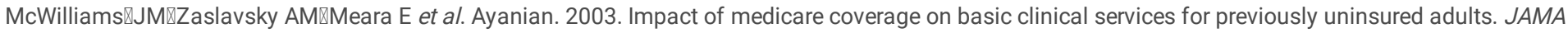
290: 757-64.

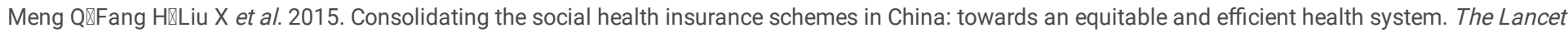
386: $1484-92$.

Meng Q $₫$ Xu K. 2014. Progress and challenges of the rural cooperative medical scheme in China. Bulletin of the World Health Organization 92: $447-51$.

Meng X. 2012. Labor market outcomes and reforms in China. The Journal of Economic Perspectives 26: 75-101.

Ministry of health. (2012). China Health Statistical Yearbook 2012.

Mjelde-Mossey LA囚Chi I囚Lou VWQ. 2006. Relationship between adherence to tradition and depression in chinese elders in China. Aging \& Mental Health 10: 19-26.

Mou J『Cheng J『Zhang D et al. 2009. Health care utilisation amongst Shenzhen migrant workers: does being insured make a difference? BMC Health Services Research 9: 214.

National Bureau of Statistics of China. (2017). China statistical yearbook 2017. Beijing. https://www.bookdepository.com/China-Statistical-Yearbook-2017National-Bureau-Statistics-China/9787503782534 (June 20, 2019).

National Health and Family Planning Commission. (2015). China floating population development report. Beijing: China Population Press.

National Healthcare Security Administration. (2019). Notice of Accomplishing the Work on Integrated Medical Insurance Schemes in 2019. http://www.nhsa.gov.cn/art/2019/5/13/art_37_1286.html (August 26, 2019).

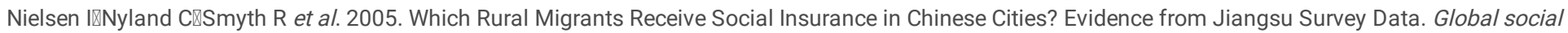
policy 5: 353-81.

Older Americans 2016: Key Indicators of Well-Being. : 204. 
Pan XY\Xu J『Meng Q. 2016. Integrating Social Health Insurance Systems in China. The Lancet 387: 1274-75.

Qiu P®Yang Y₫Zhang J et al. 2011. Rural-to-Urban Migration and Its Implication for New Cooperative Medical Scheme Coverage and Utilization in China. BMC Public Health 11: 520.

Ramesh MðWu X. 2009. Health Policy Reform in China: Lessons from Asia. Social Science \& Medicine 68: 2256-62.

Rubalcava LN囚Teruel GMखThomas D et al. 2008. The Healthy Migrant Effect: New Findings From the Mexican Family Life Survey. American Journal of Public Health 98: 78-84.

Schneider EL『Guralnik JM. 1990. The Aging of America: Impact on Health Care Costs. JAMA 263: 2335-40.

Shan LखZhao M『Ning N et al. 2018. Dissatisfaction with Current Integration Reforms of Health Insurance Schemes in China: Are They a Success and What Matters? Health Policy and Planning 33: 345-54.

Shen BJ囚Takeuchi DT. 2001. A Structural Model of Acculturation and Mental Health Status among Chinese Americans. American Journal of Community Psychology 29: 387-418.

Siu ALهUS Preventive Services Task Force. 2016. Screening for Breast Cancer: U.S. Preventive Services Task Force Recommendation Statement. Annals of Internal Medicine 164: 279-96.

Smith JP『Strauss J囚Zhao Y. 2014. Healthy Aging in China. The journal of the economics of ageing 4: 37-43.

Tang Z. 2013. The Great Migration: Rural-Urban Migration in China and Indonesia. Canadian Studies in Population 39: 129-30.

The General Office of the State Council of China. (2016). Opinions of the State Council on Integrating the Basic Medical Insurance Systems for Urban and Rural Residents. http://www.mohrss.gov.cn/SYrlzyhshbzb/shehuibaozhang/zcwj/yiliao/201601/t20160112_231624.html.

The State Council. (2018). Introduction of Institution Reform in the State Council. http://www.xinhuanet.com/politics/2018lh/2018-03/14/c_1122533011.htm (August 26, 2019).

United Nations. (2016). Goal 3 ... Sustainable Development Knowledge Platform. https://sustainabledevelopment.un.org/sdg3 (August 26, 2019).

Wang HQ囚Liu ZH $₫ Z$ hang YZ et al. 2012. Integration of Current Identity-Based District-Varied Health Insurance Schemes in China: Implications and Challenges. Frontiers of Medicine 6: 79-84.

Wang J『Zhao X. 2012. Family Functioning and Social Support for Older Patients with Depression in an Urban Area of Shanghai, China. Archives of Gerontology and Geriatrics 55: 574-79.

Wang JC『Martin B. 2012. Aging and Atherosclerosis. Circulation Research 111: 245-59.

Wang Q. (2017). Health of the Elderly Migration Population in China: Benefit from Individual and Local Socioeconomic Status? International Journal of Environmental Research and Public Health 14(4). https://www.ncbi.nlm.nih.gov/pmc/articles/PMC5409571/ (August 14, 2019).

Wu B囚Tran TV囚Amjad QA. 2004. Chronic illnesses and depression among chinese immigrant elders. Journal of Gerontological Social Work 43: $79-95$.

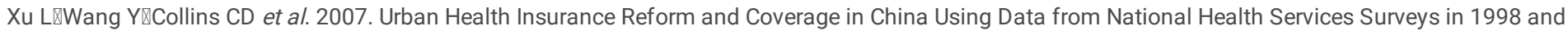
2003. BMC Health Services Research 7: 37.

Yang CøLiu Y. 2014. Path Choice and Effect Analysis of Integration of Urban and Rural Medical Insurance Scheme - Based on the Practice of Changsha City. China Health Insur 5: 16-18.

Yang W₫Wu X. 2015. Paying for Outpatient Care in Rural China: Cost Escalation under China's New Co-Operative Medical Scheme. Health Policy and Planning 30: 187-96.

Yeh AG囚Xu J『Liu K. (2011). China's Post-Reform Urbanization: Retrospect, Policies and Trends. London: IIED [u.a.].

Zhang ZQ『Zhou Y凶Lu SX et al. 2007. Return Migration of Rural Laborer from Western China: Causes and Strategies. Stat Res 24: 9-15.

Zhao Y. 1999. Leaving the Countryside: Rural-To-Urban Migration Decisions in China. The American Economic Review 89: $281-86$.

Zheng G. 2014. Analysis and Recommendations for Integrating the Urban and Rural Health Insurance Schemes. China Health Insur 2: 8-11.

\section{Tables}

Table 1 Descriptive Statistics of Main Variables by Types of Health Insurance Schemes 


\begin{tabular}{|c|c|c|c|c|c|c|c|c|}
\hline & Non-IMISs & & IMISs & & NCMSs & & URBMIs & \\
\hline Variable & Mean & Std. Dev. & Mean & Std. Dev. & Mean & Std. Dev. & Mean & Std. Dev. \\
\hline inpa & 0.080 & 0.272 & 0.096 & 0.295 & 0.082 & 0.275 & 0.069 & $0.254^{\star \star}$ \\
\hline local_inpa & $0.058^{\star \star}$ & 0.234 & 0.081 & 0.274 & $0.059 * *$ & 0.235 & 0.056 & $0.231^{\star \star}$ \\
\hline less_serious_doctor & 0.451 & 0.498 & 0.459 & 0.499 & 0.447 & 0.497 & 0.475 & 0.500 \\
\hline need_inpa & 0.098 & 0.298 & 0.108 & 0.311 & 0.100 & 0.300 & 0.089 & 0.285 \\
\hline self-reported health status & 3.313 & 0.722 & 3.355 & 0.718 & $3.306^{*}$ & 0.725 & 3.356 & 0.703 \\
\hline $\begin{array}{l}\text { hypertension or diabetes } \\
\text { ( } 1=\text { have, } 0=\text { no) }\end{array}$ & 0.217 & 0.412 & 0.211 & 0.408 & 0.212 & 0.408 & 0.250 & $0.433^{*}$ \\
\hline age & 66.544 & 6.140 & 66.690 & 6.293 & 66.491 & 6.152 & 66.861 & 6.058 \\
\hline gender ( 1 =male, $0=$ female $)$ & 0.512 & 0.500 & 0.506 & 0.500 & 0.518 & 0.500 & 0.469 & 0.499 \\
\hline Education & $2.135^{\star \star \star}$ & 0.876 & 2.312 & 0.906 & $2.038^{\star \star \star}$ & 0.807 & 2.717 & $1.036 * \star \star$ \\
\hline marriage ( $1=y e s, 0=$ no) & $0.794 * \star$ & 0.405 & 0.827 & 0.379 & $0.784^{\star \star}$ & 0.412 & 0.850 & 0.357 \\
\hline ethnic ( $1=$ han, $0=$ minority) & $0.901^{\star \star \star}$ & 0.298 & 0.943 & 0.232 & $0.898 * \star \star$ & 0.302 & 0.918 & $0.274^{*}$ \\
\hline hukou (1=rural, $0=$ =urban) & $0.852^{\star \star \star}$ & 0.355 & 0.569 & 0.496 & $0.951 * \star \star$ & 0.216 & 0.256 & 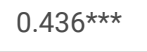 \\
\hline $\begin{array}{l}\text { household incomes per capita } \\
\text { per month }\end{array}$ & 1918.866 & 11869.640 & 2091.701 & 1984.529 & 1865.950 & 12790.580 & 2238.668 & 1826.181 \\
\hline $\begin{array}{l}\text { household expenditure per } \\
\text { capita per month }\end{array}$ & $959.597^{\star \star \star}$ & 714.009 & 1109.474 & 780.363 & $917.887 * \star \star$ & 677.181 & 1211.721 & $863.547 * \star$ \\
\hline $\begin{array}{l}\text { household food expenditure per } \\
\text { capita per month }\end{array}$ & $423.231^{\star \star \star *}$ & 281.020 & 496.829 & 342.393 & $404.087 * \star \star$ & 265.220 & 539.101 & $340.100 * *$ \\
\hline $\begin{array}{l}\text { household house expenditure } \\
\text { per capita per month }\end{array}$ & 179.260 *** & 298.014 & 231.996 & 290.534 & $173.898^{\star \star *}$ & 280.378 & 211.512 & 386.469 \\
\hline Number of friends in residence & $7.486^{\star \star \star *}$ & 9.401 & 8.562 & 8.884 & $7.170 * \star \star$ & 8.951 & 9.390 & 11.585 \\
\hline years since migration & $6.674^{\star \star \star}$ & 6.704 & 5.380 & 5.206 & 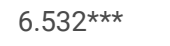 & 6.505 & 7.523 & $7.747 \star \star \star$ \\
\hline fitness_time per day (min) & $62.302^{\star \star \star}$ & 45.562 & 73.432 & 48.234 & $60.413^{\star \star \star}$ & 45.259 & 73.694 & 45.732 \\
\hline $\begin{array}{l}\text { Health examination in the past } \\
\text { one year }\end{array}$ & $0.315^{\star \star \star}$ & 0.465 & 0.447 & 0.498 & 0.301 *** & 0.459 & 0.400 & $0.490^{\star}$ \\
\hline \multicolumn{9}{|l|}{ Main source of income } \\
\hline 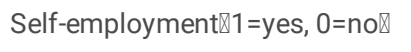 & $0.279 \star \star \star$ & 0.448 & 0.232 & 0.422 & $0.296 * \star \star$ & 0.456 & 0.176 & $0.381 * \star \star$ \\
\hline $\begin{array}{l}\text { Pension and Savings } ₫ 1=y e s, \\
0=\text { no } \\
end{array}$ & 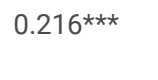 & 0.412 & 0.387 & 0.487 & $0.158^{\star \star \star}$ & 0.364 & 0.569 & $0.495^{\star \star \star}$ \\
\hline $\begin{array}{l}\text { Support from other family } \\
\text { numbers } ₫ 1=y e s, 0=\text { no } \rrbracket\end{array}$ & $0.428 * \star \star$ & 0.495 & 0.312 & 0.464 & $0.466^{\star \star \star}$ & 0.499 & 0.198 & $0.399 * \star \star$ \\
\hline Others $₫ 1=$ yes, $0=$ no $\bigotimes$ & 0.077 & 0.266 & 0.069 & 0.254 & 0.080 & 0.272 & 0.056 & 0.231 \\
\hline$N$ & 7250 & & 664 & & 6222 & & 1029 & \\
\hline
\end{tabular}

Note: ${ }^{*} p<0.1{ }^{* *} p<0.05,{ }^{* \star} p<0.01$, representing statistical significance compared with IMISs. Non-IMISs, IMISs, NCMSs, URBMIs represent Migrants Parents who have not joined IMIS and who joined IMIS, NCMS and URBMI, while Non-IMISs is the combination of NCMSs and URBMIs. Self-reported health status include no self-care ability, poor but with self-care ability, fair and good, ranked from 1 to 4; Education includes no formal education, elementary school, middle school, high school/vocational school, and college and above, ranked from 1 to 5 . Both self-reported health status and education are considered as continuous variable in this paper.

Table 2 Comparison of Health Care Utilization of Migrant Parents in Residency between IMISs and non-IMISs 


\begin{tabular}{|c|c|c|c|c|c|c|c|c|}
\hline & (1) & (2) & (3) & (4) & (5) & (6) & (7) & (8) \\
\hline & inpa & inpa & inpa & local_inpa & local_inpa & local_inpa & less_serious_doctor & less_serious_doc \\
\hline \multirow[t]{2}{*}{ imis } & $0.0315^{\star \star}$ & $0.0315^{\star \star}$ & $0.0163^{\star \star}$ & $0.0330^{\star \star \star}$ & $0.0337^{\star \star \star}$ & $0.0226^{\star \star \star}$ & $0.0446^{*}$ & 0.0401 \\
\hline & $(0.0128)$ & $(0.0127)$ & $(0.00749)$ & $(0.0121)$ & $(0.0119)$ & $(0.00809)$ & $(0.0269)$ & $(0.0250)$ \\
\hline \multirow[t]{2}{*}{ need_inpa } & & & $0.818^{\star \star \star}$ & & & $0.594^{\star \star \star}$ & & \\
\hline & & & $(0.0173)$ & & & $(0.0242)$ & & \\
\hline \multirow[t]{2}{*}{$\begin{array}{l}\text { self-reported } \\
\text { health status }\end{array}$} & $-0.0811^{\star \star \star}$ & $-0.0735^{\star \star \star}$ & -0.00194 & $-0.0632^{\star \star \star}$ & $-0.0575^{\star \star \star}$ & -0.00558 & 0.00617 & 0.00873 \\
\hline & $(0.00713)$ & $(0.00748)$ & $(0.00307)$ & $(0.00655)$ & $(0.00681)$ & $(0.00430)$ & $(0.0110)$ & $(0.0109)$ \\
\hline \multirow{2}{*}{$\begin{array}{l}\text { Having } \\
\text { hypertension or } \\
\text { diabetes }\end{array}$} & $0.100^{\star \star \star}$ & $0.0958^{\star \star \star}$ & 0.00470 & $0.0854^{\star \star \star}$ & $0.0823^{\star \star \star}$ & $0.0162^{\star \star}$ & $0.0347^{\star \star}$ & $0.0335^{\star \star}$ \\
\hline & $(0.0115)$ & $(0.0112)$ & $(0.00410)$ & $(0.0110)$ & $(0.0108)$ & $(0.00645)$ & $(0.0151)$ & $(0.0148)$ \\
\hline \multirow{2}{*}{$\begin{array}{l}\text { Fitness time per } \\
\text { day (min) }\end{array}$} & 0.000134 & 0.0000815 & 0.0000116 & 0.0000971 & 0.0000489 & -0.00000183 & $0.000351^{\star *}$ & 0.000181 \\
\hline & $(0.0000876)$ & $(0.0000852)$ & $(0.0000343)$ & $(0.0000786)$ & $(0.0000769)$ & $(0.0000434)$ & $(0.000156)$ & $(0.000153)$ \\
\hline \multirow{2}{*}{$\begin{array}{l}\text { Health } \\
\text { examination in } \\
\text { the past one year }\end{array}$} & -0.00183 & -0.00293 & -0.00360 & 0.00305 & 0.00182 & 0.00134 & $0.0755^{\star \star \star}$ & $0.0715^{\star \star \star}$ \\
\hline & $(0.00821)$ & $(0.00811)$ & $(0.00357)$ & $(0.00803)$ & (0.00788) & $(0.00461)$ & $(0.0204)$ & $(0.0205)$ \\
\hline \multirow[t]{2}{*}{ age } & $0.00153^{\star *}$ & 0.000946 & 0.000113 & $0.00113^{*}$ & 0.000631 & 0.0000274 & $0.00488^{\star \star \star}$ & $0.00321^{\star *}$ \\
\hline & $(0.000691)$ & $(0.000761)$ & $(0.000271)$ & $(0.000630)$ & $(0.000689)$ & $(0.000392)$ & $(0.00122)$ & $(0.00127)$ \\
\hline male & 0.00793 & $0.0126^{\star *}$ & 0.00258 & 0.00547 & $0.00823^{*}$ & 0.000999 & $-0.0365^{\star \star \star}$ & $-0.0236^{\star *}$ \\
\hline $\begin{array}{l}\text { (reference group: } \\
\text { female) }\end{array}$ & $(0.00562)$ & $(0.00587)$ & $(0.00280)$ & $(0.00491)$ & $(0.00497)$ & $(0.00345)$ & $(0.00845)$ & (0.00950) \\
\hline Married & 0.00237 & 0.000302 & 0.000569 & -0.00316 & -0.00437 & -0.00418 & -0.0171 & -0.0107 \\
\hline $\begin{array}{l}\text { (reference group: } \\
\text { Unmarried) }\end{array}$ & $(0.00887)$ & $(0.00873)$ & $(0.00415)$ & $(0.00767)$ & $(0.00758)$ & $(0.00516)$ & $(0.0161)$ & $(0.0167)$ \\
\hline Han ethnic & -0.000451 & 0.00125 & 0.00373 & -0.00464 & -0.00464 & -0.00285 & -0.0280 & -0.0322 \\
\hline $\begin{array}{l}\text { (reference group: } \\
\text { minority) }\end{array}$ & $(0.0127)$ & $(0.0127)$ & $(0.00752)$ & $(0.0115)$ & $(0.0116)$ & $(0.0100)$ & $(0.0281)$ & $(0.0273)$ \\
\hline $\begin{array}{l}\text { Elementary } \\
\text { school }\end{array}$ & & 0.00266 & -0.00218 & & -0.00233 & -0.00584 & & -0.0170 \\
\hline $\begin{array}{l}\text { (reference group: } \\
\text { no formal } \\
\text { education) }\end{array}$ & & $(0.00986)$ & $(0.00443)$ & & $(0.00790)$ & $(0.00499)$ & & $(0.0178)$ \\
\hline Middle school & & -0.0157 & $-0.0102^{\star *}$ & & -0.0127 & -0.00867 & & 0.000487 \\
\hline $\begin{array}{l}\text { (reference group: } \\
\text { no formal } \\
\text { education) }\end{array}$ & & $(0.0118)$ & $(0.00515)$ & & $(0.00988)$ & $(0.00574)$ & & $(0.0213)$ \\
\hline $\begin{array}{l}\text { High } \\
\text { school/vocational } \\
\text { school }\end{array}$ & & 0.000738 & -0.00193 & & 0.00700 & 0.00507 & & -0.0170 \\
\hline $\begin{array}{l}\text { (reference group: } \\
\text { no formal } \\
\text { education) }\end{array}$ & & $(0.0162)$ & $(0.00682)$ & & $(0.0145)$ & (0.00799) & & $(0.0384)$ \\
\hline college and above & & $-0.0709^{\star \star \star}$ & $-0.0225^{*}$ & & $-0.0621^{\star \star \star}$ & $-0.0270^{*}$ & & -0.0617 \\
\hline $\begin{array}{l}\text { (reference group: } \\
\text { no formal } \\
\text { education) }\end{array}$ & & $(0.0187)$ & $(0.0136)$ & & $(0.0171)$ & $(0.0145)$ & & $(0.0604)$ \\
\hline rural & & 0.0101 & 0.000679 & & 0.00742 & 0.000608 & & -0.0321 \\
\hline $\begin{array}{l}\text { (reference group: } \\
\text { urban) }\end{array}$ & & $(0.00892)$ & $(0.00527)$ & & $(0.00799)$ & $(0.00585)$ & & $(0.0206)$ \\
\hline In_income & & -0.00474 & -0.000639 & & 0.00472 & $0.00770^{\star \star}$ & & $0.0275^{\star \star}$ \\
\hline
\end{tabular}

Page 13/18 


\begin{tabular}{|c|c|c|c|c|c|c|c|c|}
\hline & & $(0.00521)$ & $(0.00211)$ & & (0.00319) & $(0.00327)$ & & $(0.0120)$ \\
\hline \multicolumn{2}{|l|}{ In_expenditure } & 0.0166 & -0.000869 & & 0.00600 & -0.00663 & & -0.0205 \\
\hline & & $(0.0108)$ & $(0.00423)$ & & (0.00788) & $(0.00527)$ & & $(0.0215)$ \\
\hline \multicolumn{2}{|l|}{$\begin{array}{l}\text { In_food } \\
\text { expenditure }\end{array}$} & -0.00831 & 0.00225 & & -0.00677 & 0.000888 & & -0.000658 \\
\hline & & $(0.00773)$ & $(0.00361)$ & & (0.00669) & $(0.00443)$ & & $(0.0155)$ \\
\hline \multicolumn{2}{|l|}{$\begin{array}{l}\text { In_house__ } \\
\text { expenditure }\end{array}$} & -0.000830 & -0.000593 & & -0.000495 & -0.000323 & & $-0.00820^{\star *}$ \\
\hline & & $(0.00154)$ & $(0.000736)$ & & $(0.00136)$ & (0.000929) & & $(0.00377)$ \\
\hline \multicolumn{9}{|l|}{$\begin{array}{l}\text { Main source of } \\
\text { income }\end{array}$} \\
\hline $\begin{array}{l}\text { Pension and } \\
\text { Savings }\end{array}$ & & $0.0279^{\star *}$ & $-0.0151^{\star *}$ & & $0.0252^{* *}$ & -0.00598 & & 0.0417 \\
\hline $\begin{array}{l}\text { (reference group: } \\
\text { self-employment) }\end{array}$ & & $(0.0137)$ & $(0.00688)$ & & $(0.0120)$ & (0.00799) & & $(0.0298)$ \\
\hline $\begin{array}{l}\text { Support from } \\
\text { other family } \\
\text { numbers }\end{array}$ & & 0.0110 & $-0.0143^{\star *}$ & & 0.0152 & -0.00315 & & $0.0585^{\star \star}$ \\
\hline $\begin{array}{l}\text { (reference group: } \\
\text { self-employment) }\end{array}$ & & $(0.0131)$ & $(0.00638)$ & & $(0.0123)$ & $(0.00756)$ & & $(0.0280)$ \\
\hline Others & & 0.0109 & $-0.0145^{*}$ & & 0.00732 & -0.0111 & & -0.0179 \\
\hline $\begin{array}{l}\text { (reference group: } \\
\text { self-employment) }\end{array}$ & & $(0.0183)$ & $(0.00755)$ & & $(0.0163)$ & $(0.00996)$ & & $(0.0336)$ \\
\hline \multicolumn{2}{|l|}{$\begin{array}{l}\text { Number of friends } \\
\text { in residence }\end{array}$} & 0.000474 & 0.0000575 & & 0.000582 & 0.000280 & & $0.00251^{* \star *}$ \\
\hline & & $(0.000450)$ & $(0.000152)$ & & $(0.000388)$ & $(0.000250)$ & & $(0.000959)$ \\
\hline \multicolumn{2}{|l|}{$\begin{array}{l}\text { years since } \\
\text { migration }\end{array}$} & 0.000649 & 0.000408 & & $0.00140^{\star \star \star}$ & $0.00122^{\star \star \star}$ & & -0.00107 \\
\hline & & $(0.000557)$ & $(0.000302)$ & & $(0.000519)$ & $(0.000366)$ & & $(0.00122)$ \\
\hline \multicolumn{2}{|l|}{$\begin{array}{l}\text { Main source of } \\
\text { income }\end{array}$} & 0.0141 & $0.0242^{\star \star \star}$ & & 0.00457 & 0.0119 & & 0.0198 \\
\hline & & $(0.0123)$ & $(0.00773)$ & & $(0.0115)$ & $(0.00791)$ & & (0.0293) \\
\hline $\begin{array}{l}\text { Fixed effects of } \\
\text { origin provinces }\end{array}$ & $\sqrt{ }$ & $\sqrt{ }$ & $\sqrt{ }$ & $\sqrt{ }$ & $\sqrt{ }$ & $\sqrt{ }$ & $\sqrt{ }$ & $\sqrt{ }$ \\
\hline $\begin{array}{l}\text { Fixed effects of } \\
\text { flow-in cities }\end{array}$ & $\sqrt{ }$ & $\sqrt{ }$ & $\sqrt{ }$ & $\sqrt{ }$ & $\sqrt{ }$ & $\sqrt{ }$ & $\sqrt{ }$ & $\sqrt{ }$ \\
\hline \multirow[t]{2}{*}{ _cons } & $0.121^{*}$ & 0.0781 & $0.0588^{*}$ & $0.163^{\star \star \star}$ & 0.114 & $0.0996^{* *}$ & $0.591^{\star \star \star}$ & $0.702^{\star \star \star}$ \\
\hline & $(0.0616)$ & $(0.0835)$ & $(0.0319)$ & $(0.0589)$ & $(0.0776)$ & $(0.0486)$ & $(0.122)$ & $(0.175)$ \\
\hline$N$ & 7919 & 7912 & 7912 & 7919 & 7912 & 7912 & 7919 & 7912 \\
\hline
\end{tabular}

Note: Robust standard errors are reported in parentheses. ${ }^{*} p<0.1,{ }^{* *} p<0.05,{ }^{* \star}{ }^{*} p<0.01$. The dependent variable of Columns (1) $-(3)$ is inpa; the dependent variable of Columns (4) - (6) is local_inpa; the dependent variable of Columns (7) - (8) is less_serious_doctor. The Column (1), (4) and (7) only control health status, health behaviors, individual demographic characteristics and city fixed effect. The Column (2), (5) and (8) also controls SES, including education, income, expenditure and immigration information, on the basis of Column (1), (4) and (7). The Column (3) and (6) also controls need_inpa on the basis of Column (2) and (5). Since the dependent variable of Column (7) and (8) is less_serious_doctor (the circumstance that the Migrant Parents do not need inpatient services), we do not control need_inpa in these two columns.

Table 3 Comparison of Health Care Utilization of Migrant Parents in Residency between IMISs and NCMSs 


\begin{tabular}{|c|c|c|c|c|c|c|c|c|}
\hline & (1) & (2) & (3) & (4) & (5) & (6) & (7) & (8) \\
\hline & inpa & inpa & inpa & local_inpa & local_inpa & local_inpa & less_serious_doctor & less_serious_doctor \\
\hline \multirow[t]{2}{*}{ imis } & $0.0338^{* \star}$ & $0.0232^{*}$ & $0.0109^{\star}$ & $0.0367^{\star \star \star}$ & $0.0283^{* *}$ & $0.0195^{\star \star \star}$ & $0.0572^{* \star}$ & 0.0436 \\
\hline & $(0.0139)$ & $(0.0141)$ & $(0.00646)$ & $(0.0130)$ & $(0.0129)$ & $(0.00728)$ & $(0.0287)$ & $(0.0310)$ \\
\hline need_inpa & & & $\sqrt{ }$ & & & $\sqrt{ }$ & & \\
\hline Other control variables & $\sqrt{ }$ & $\sqrt{ }$ & $\sqrt{ }$ & $\sqrt{ }$ & $\sqrt{ }$ & $\sqrt{ }$ & $\sqrt{ }$ & $\sqrt{ }$ \\
\hline SES & & $\sqrt{ }$ & $\sqrt{ }$ & & $\sqrt{ }$ & $\sqrt{ }$ & & $\sqrt{ }$ \\
\hline $\begin{array}{l}\text { Fixed effects of origin } \\
\text { provinces }\end{array}$ & $\sqrt{ }$ & $\sqrt{ }$ & $\sqrt{ }$ & $\sqrt{ }$ & $\sqrt{ }$ & $\sqrt{ }$ & $\sqrt{ }$ & $\sqrt{ }$ \\
\hline Fixed effects of flow-in cities & $\sqrt{ }$ & $\sqrt{ }$ & $\sqrt{ }$ & $\sqrt{ }$ & $\sqrt{ }$ & $\sqrt{ }$ & $\sqrt{ }$ & $\sqrt{ }$ \\
\hline$N$ & 6891 & 6885 & 6885 & 6891 & 6885 & 6885 & 6891 & 6885 \\
\hline
\end{tabular}

Note: Robust standard errors are reported in parentheses. ${ }^{*} p<0.1, * \star p<0.05,{ }^{* \star *} p<0.01$. Other control variables include individual demographic characteristic, self-reported health status, having hypertension or diabetes, fitness time, having health examination or not in the past year. SES includes education, income, expenditure and immigration information. Omit specific results. Same structure of dependent variable as in table 2.

Table 4 Comparison of Health Care Utilization of Migrant Parents in Residency between IMISs and. URBMIs

\begin{tabular}{|llllllllll}
\hline & $(1)$ & $(2)$ & $(3)$ & $(4)$ & $(5)$ & $(6)$ & $(7)$ & $(8)$ \\
\hline imis & inpa & inpa & inpa & local_inpa & local_inpa & local_inpa & less_serious_doctor & less_serious_doctor \\
\hline & $0.0358^{*}$ & 0.0327 & $0.0172^{* *}$ & $0.0341^{*}$ & 0.0322 & $0.0195^{*}$ & 0.0347 & 0.0228 \\
\hline need_inpa & $(0.0199)$ & $(0.0200)$ & $(0.00711)$ & $(0.0201)$ & $(0.0209)$ & $(0.0109)$ & $(0.0442)$ \\
\hline Other control variables & $\sqrt{ }$ & $\sqrt{ }$ & $\sqrt{ }$ & $\sqrt{ }$ & $\sqrt{ }$ & $\sqrt{ }$ & $\sqrt{ }$ & \\
\hline SES & & $\sqrt{ }$ & $\sqrt{ }$ & & $\sqrt{ }$ & $\sqrt{ }$ & & $\sqrt{ }$ \\
\hline $\begin{array}{l}\text { Fixed effects of origin } \\
\text { provinces }\end{array}$ & $\sqrt{ }$ & $\sqrt{ }$ & $\sqrt{ }$ & $\sqrt{ }$ & $\sqrt{ }$ & $\sqrt{ }$ & $\sqrt{ }$ \\
\hline Fixed effects of flow-in cities & $\sqrt{ }$ & $\sqrt{ }$ & $\sqrt{ }$ & $\sqrt{ }$ & $\sqrt{ }$ & $\sqrt{ }$ & $\sqrt{ }$ \\
\hline$N$ & 1692 & 1691 & 1691 & 1692 & 1691 & 1691 & 1692 \\
\hline
\end{tabular}

Note: Robust standard errors are reported in parentheses. ${ }^{*} p<0.1,{ }^{* *} p<0.05, * \star * p<0.01$. Other control variables include individual demographic characteristic, self-reported health status, having hypertension or diabetes, fitness time, having health examination or not in the past year. SES includes education, income, expenditure and immigration information. Omit specific results. Same structure of dependent variable as in table 2.

Table 5 Comparison of Health Care Utilization of Migrant Parents between IMISs and. URBMIs after the Adjustment of Insurance Type 


\begin{tabular}{|c|c|c|c|c|c|c|c|c|c|}
\hline & (1) & (2) & (3) & (4) & (5) & (6) & (7) & (8) & (9) \\
\hline & \multicolumn{3}{|c|}{ IMISs vs. non-IMISs } & \multicolumn{3}{|c|}{ IMISs vs. NCMSs } & \multicolumn{3}{|c|}{ IMISs vs. URBMIs } \\
\hline & inpa & local_inpa & less_serious_doctor & inpa & local_inpa & less_serious_doctor & inpa & local_inpa & less_ser \\
\hline \multirow[t]{2}{*}{ imis } & $0.0147^{\star *}$ & $0.0244^{\star \star \star}$ & $0.0431^{*}$ & $0.0109^{\star}$ & $0.0195^{\star \star \star}$ & 0.0436 & $0.0321^{\star \star \star}$ & 0.0228 & 0.0125 \\
\hline & $(0.00596)$ & $(0.00696)$ & $(0.0227)$ & $(0.00646)$ & $(0.00728)$ & $(0.0310)$ & $(0.00968)$ & $(0.0525)$ & $(0.0561)$ \\
\hline need_inpa & $\sqrt{ }$ & $\sqrt{ }$ & & $\sqrt{ }$ & $\sqrt{ }$ & & $\sqrt{ }$ & $\sqrt{ }$ & \\
\hline $\begin{array}{l}\text { Other } \\
\text { control } \\
\text { variables }\end{array}$ & $\sqrt{ }$ & $\sqrt{ }$ & $\sqrt{ }$ & $\sqrt{ }$ & $\sqrt{ }$ & $\sqrt{ }$ & $\sqrt{ }$ & $\sqrt{ }$ & $\sqrt{ }$ \\
\hline SES & $\sqrt{ }$ & $\sqrt{ }$ & $\sqrt{ }$ & $\sqrt{ }$ & $\sqrt{ }$ & $\sqrt{ }$ & $\sqrt{ }$ & $\sqrt{ }$ & $\sqrt{ }$ \\
\hline $\begin{array}{l}\text { Fixed } \\
\text { effects of } \\
\text { origin } \\
\text { provinces }\end{array}$ & $\sqrt{ }$ & $\sqrt{ }$ & $\sqrt{ }$ & $\sqrt{ }$ & $\sqrt{ }$ & $\sqrt{ }$ & $\sqrt{ }$ & $\sqrt{ }$ & $\sqrt{ }$ \\
\hline $\begin{array}{l}\text { Fixed } \\
\text { effects of } \\
\text { flow-in } \\
\text { cities }\end{array}$ & $\sqrt{ }$ & $\sqrt{ }$ & $\sqrt{ }$ & $\sqrt{ }$ & $\sqrt{ }$ & $\sqrt{ }$ & $\sqrt{ }$ & $\sqrt{ }$ & $\sqrt{ }$ \\
\hline$N$ & 7912 & 7912 & 7912 & 6885 & 6885 & 6885 & 1691 & 1691 & 1691 \\
\hline
\end{tabular}

Note: Robust standard errors are reported in parentheses. ${ }^{*} p<0.1, * \star p<0.05,{ }^{* \star} p<0.01$. Other control variables include individual demographic characteristic, self-reported health status, having hypertension or diabetes, fitness time, having health examination or not in the past year. SES includes education, income, expenditure and immigration information. Same structure of dependent variable as in table 2. The columns (1)-(3) and (4)-(6) have same structure as column (3), (6) and (8) in table 2. The columns (7)-(9) have same structure as column (3), (6) and (8) in table 4 . In this regression, we redefine the potentially misreported insurance type, considering samples who are rural residents with agriculture hukou as IMISs.

Table 6 Comparison of Health Care Utilization of Migrant Parents between IMISs and. URBMIs after Dropping Repeated Enrollment

\begin{tabular}{|c|c|c|c|c|c|c|c|c|c|}
\hline & (1) & $(2)$ & (3) & (4) & (5) & (6) & (7) & (8) & (9) \\
\hline & \multicolumn{3}{|c|}{ IMISs vs. non-IMISs } & \multicolumn{3}{|c|}{ IMISs vs. NCMSs } & \multicolumn{3}{|c|}{ IMISs vs. URBMIs } \\
\hline & inpa & local_inpa & less_serious_doctor & inpa & local_inpa & less_serious_doctor & inpa & local_inpa & less_ser \\
\hline \multirow[t]{2}{*}{ imis } & $0.0162^{\star *}$ & $0.0244^{\star \star \star}$ & $0.0443^{\star}$ & 0.00960 & $0.0212^{\star \star \star}$ & $0.0550 *$ & $0.0190 * *$ & $0.0246 * *$ & 0.0351 \\
\hline & $(0.00772)$ & $(0.00874)$ & $(0.0262)$ & $(0.00633)$ & $(0.00752)$ & $(0.0316)$ & $(0.00760)$ & $(0.0110)$ & $(0.0559)$ \\
\hline need_inpa & $\sqrt{ }$ & $\sqrt{ }$ & & $\sqrt{ }$ & $\sqrt{ }$ & & $\sqrt{ }$ & $\sqrt{ }$ & \\
\hline $\begin{array}{l}\text { Other } \\
\text { control } \\
\text { variables }\end{array}$ & $\sqrt{ }$ & $\sqrt{ }$ & $\sqrt{ }$ & $\sqrt{ }$ & $\sqrt{ }$ & $\sqrt{ }$ & $\sqrt{ }$ & $\sqrt{ }$ & $\sqrt{ }$ \\
\hline SES & $\sqrt{ }$ & $\sqrt{ }$ & $\sqrt{ }$ & $\sqrt{ }$ & $\sqrt{ }$ & $\sqrt{ }$ & $\sqrt{ }$ & $\sqrt{ }$ & $\sqrt{ }$ \\
\hline $\begin{array}{l}\text { Fixed } \\
\text { effects of } \\
\text { origin } \\
\text { provinces }\end{array}$ & $\sqrt{ }$ & $\sqrt{ }$ & $\sqrt{ }$ & $\sqrt{ }$ & $\sqrt{ }$ & $\sqrt{ }$ & $\sqrt{ }$ & $\sqrt{ }$ & $\sqrt{ }$ \\
\hline $\begin{array}{l}\text { Fixed } \\
\text { effects of } \\
\text { flow-in } \\
\text { cities }\end{array}$ & $\sqrt{ }$ & $\sqrt{ }$ & $\sqrt{ }$ & $\sqrt{ }$ & $\sqrt{ }$ & $\sqrt{ }$ & $\sqrt{ }$ & $\sqrt{ }$ & $\sqrt{ }$ \\
\hline$N$ & 7404 & 7404 & 7404 & 6442 & 6442 & 6442 & 1626 & 1626 & 1626 \\
\hline
\end{tabular}

Note: Robust standard errors are reported in parentheses. ${ }^{*} p<0.1,{ }^{* \star} p<0.05,{ }^{* \star} p<0.01$. Other control variables include individual demographic characteristic, self-reported health status, having hypertension or diabetes, fitness time, having health examination or not in the past year. SES includes education, income, expenditure and immigration information. Same structure of dependent variable as in table 2. The columns (1)-(3) have same structure as column (3), (6) and (8) in table 2. The columns (4)-(6) have same structure as column (3), (6) and (8) in table 3 . The columns (7)-(9) have same structure as column (3), (6) and (8) in table 4. In this regression, we drop the samples who joined the insurances type repeatedly.

Table 7 Comparison of Health Care Utilization of Migrant Parents between IMISs and. URBMIs after Dropping Individuals Who Changed hukou 


\begin{tabular}{|c|c|c|c|c|c|c|c|c|c|}
\hline & (1) & (2) & (3) & (4) & (5) & (6) & (7) & (8) & (9) \\
\hline & \multicolumn{3}{|c|}{ IMISs vs. non-IMISs } & \multicolumn{3}{|c|}{ IMISs vs. NCMSs } & \multicolumn{3}{|c|}{ IMISs vs. URBMIs } \\
\hline & inpa & local_inpa & less_serious_doctor & inpa & local_inpa & less_serious_doctor & inpa & local_inpa & less_ser \\
\hline \multirow[t]{2}{*}{ imis } & $0.0173^{* *}$ & $0.0238^{\star \star \star}$ & $0.0448^{*}$ & $0.0115^{\star}$ & $0.0199^{\star \star \star}$ & 0.0493 & $0.0187^{* \star}$ & $0.0188^{*}$ & 0.0223 \\
\hline & $(0.00778)$ & $(0.00805)$ & $(0.0248)$ & $(0.00676)$ & $(0.00751)$ & $(0.0314)$ & $(0.00724)$ & $(0.0103)$ & $(0.0522)$ \\
\hline need_inpa & $\sqrt{ }$ & $\sqrt{ }$ & & $\sqrt{ }$ & $\sqrt{ }$ & & $\sqrt{ }$ & $\sqrt{ }$ & \\
\hline $\begin{array}{l}\text { Other } \\
\text { control } \\
\text { variables }\end{array}$ & $\sqrt{ }$ & $\sqrt{ }$ & $\sqrt{ }$ & $\sqrt{ }$ & $\sqrt{ }$ & $\sqrt{ }$ & $\sqrt{ }$ & $\sqrt{ }$ & $\sqrt{ }$ \\
\hline SES & $\sqrt{ }$ & $\sqrt{ }$ & $\sqrt{ }$ & $\sqrt{ }$ & $\sqrt{ }$ & $\sqrt{ }$ & $\sqrt{ }$ & $\sqrt{ }$ & $\sqrt{ }$ \\
\hline $\begin{array}{l}\text { Fixed } \\
\text { effects of } \\
\text { origin } \\
\text { provinces }\end{array}$ & $\sqrt{ }$ & $\sqrt{ }$ & $\sqrt{ }$ & $\sqrt{ }$ & $\sqrt{ }$ & $\sqrt{ }$ & $\sqrt{ }$ & $\sqrt{ }$ & $\sqrt{ }$ \\
\hline $\begin{array}{l}\text { Fixed } \\
\text { effects of } \\
\text { flow-in } \\
\text { cities }\end{array}$ & $\sqrt{ }$ & $\sqrt{ }$ & $\sqrt{ }$ & $\sqrt{ }$ & $\sqrt{ }$ & $\sqrt{ }$ & $\sqrt{ }$ & $\sqrt{ }$ & $\sqrt{ }$ \\
\hline$N$ & 7809 & 7809 & 7809 & 6804 & 6804 & 6804 & 1669 & 1669 & 1669 \\
\hline
\end{tabular}

Note: Robust standard errors are reported in parentheses. ${ }^{*} p<0.1, * \star p<0.05,{ }^{* \star} p<0.01$. Other control variables include individual demographic characteristic, self-reported health status, having hypertension or diabetes, fitness time, having health examination or not in the past year. SES includes education, income, expenditure and immigration information. Same structure of dependent variable as in table 2. The columns (1)-(3) have same structure as column (3), (6) and (8) in table 2. The columns (4)-(6) have same structure as column (3), (6) and (8) in table 3 . The columns (7)-(9) have same structure as column (3), (6) and (8) in table 4. In this regression, we drop the the individuals who have changed the nature of hukou.

Table 8. Comparison of Health Care Utilization of Migrant Parents between IMISs and. URBMIs after Dropping the Individuals Who Moved for Medical Treatment.

\begin{tabular}{|c|c|c|c|c|c|c|c|c|c|}
\hline & (1) & (2) & (3) & (4) & (5) & (6) & (7) & (8) & (9) \\
\hline & \multicolumn{3}{|c|}{ IMISs vs. non-IMISs } & \multicolumn{3}{|c|}{ IMISs vs. NCMSs } & \multicolumn{3}{|c|}{ IMISs vs. URBMIs } \\
\hline & inpa & local_inpa & less_serious_doctor & inpa & local_inpa & less_serious_doctor & inpa & local_inpa & less_ser \\
\hline \multirow[t]{2}{*}{ imis } & $0.0151^{\star \star}$ & $0.0216^{\star \star \star}$ & 0.0412 & 0.0100 & $0.0187^{\star \star}$ & 0.0439 & $0.0160^{\star \star}$ & $0.0185^{\star}$ & 0.0278 \\
\hline & $(0.00736)$ & $(0.00812)$ & $(0.0252)$ & $(0.00644)$ & $(0.00733)$ & $(0.0315)$ & $(0.00673)$ & $(0.0107)$ & $(0.0529)$ \\
\hline need_inpa & $\sqrt{ }$ & $\sqrt{ }$ & & $\sqrt{ }$ & $\sqrt{ }$ & & $\sqrt{ }$ & $\sqrt{ }$ & \\
\hline $\begin{array}{l}\text { Other } \\
\text { control } \\
\text { variables }\end{array}$ & $\sqrt{ }$ & $\sqrt{ }$ & $\sqrt{ }$ & $\sqrt{ }$ & $\sqrt{ }$ & $\sqrt{ }$ & $\sqrt{ }$ & $\sqrt{ }$ & $\sqrt{ }$ \\
\hline SES & $\sqrt{ }$ & $\sqrt{ }$ & $\sqrt{ }$ & $\sqrt{ }$ & $\sqrt{ }$ & $\sqrt{ }$ & $\sqrt{ }$ & $\sqrt{ }$ & $\sqrt{ }$ \\
\hline $\begin{array}{l}\text { Fixed } \\
\text { effects of } \\
\text { origin } \\
\text { provinces }\end{array}$ & $\sqrt{ }$ & $\sqrt{ }$ & $\sqrt{ }$ & $\sqrt{ }$ & $\sqrt{ }$ & $\sqrt{ }$ & $\sqrt{ }$ & $\sqrt{ }$ & $\sqrt{ }$ \\
\hline $\begin{array}{l}\text { Fixed } \\
\text { effects of } \\
\text { flow-in } \\
\text { cities }\end{array}$ & $\sqrt{ }$ & $\sqrt{ }$ & $\sqrt{ }$ & $\sqrt{ }$ & $\sqrt{ }$ & $\sqrt{ }$ & $\sqrt{ }$ & $\sqrt{ }$ & $\sqrt{ }$ \\
\hline$N$ & 7845 & 7845 & 7845 & 6827 & 6827 & 6827 & 1682 & 1682 & 1682 \\
\hline
\end{tabular}

Note: Robust standard errors are reported in parentheses. ${ }^{*} p<0.1,{ }^{* *} p<0.05,{ }^{* \star} p<0.01$. Other control variables include individual demographic characteristic, self-reported health status, having hypertension or diabetes, fitness time, having health examination or not in the past year. SES includes education, income, expenditure and immigration information. Same structure of dependent variable as in table 2. The columns (1)-(3) have same structure as column (3), (6) and (8) in table 2. The columns (4)-(6) have same structure as column (3), (6) and (8) in table 3. The columns (7)-(9) have same structure as column (3), (6) and (8) in table 4. In this regression, we drop the Migrants Parents who moved for medical treatment. 
Table 9 Comparison of Health Care Utilization of Migrant Parents between IMISs and. URBMIs after Dropping the Individuals Whose YSM is Less Than One

\begin{tabular}{|c|c|c|c|c|c|c|c|c|c|}
\hline & (1) & $(2)$ & (3) & (4) & (5) & (6) & (7) & (8) & (9) \\
\hline & \multicolumn{3}{|c|}{ IMISs vs. non-IMISs } & \multicolumn{3}{|c|}{ IMISs vs. NCMSs } & \multicolumn{3}{|c|}{ IMISs vs. URBMIs } \\
\hline & inpa & local_inpa & less_serious_doctor & inpa & local_inpa & less_serious_doctor & inpa & local_inpa & less_ser \\
\hline \multirow[t]{2}{*}{ imis } & $0.0164^{*}$ & $0.0212^{\star \star}$ & 0.0354 & 0.00996 & $0.0169 \star \star$ & 0.0454 & $0.0188^{\star \star}$ & $0.0202^{\star}$ & 0.0229 \\
\hline & $(0.00906)$ & $(0.00856)$ & $(0.0267)$ & $(0.00796)$ & $(0.00745)$ & $(0.0320)$ & $(0.00751)$ & $(0.0113)$ & $(0.0554)$ \\
\hline need_inpa & $\sqrt{ }$ & $\sqrt{ }$ & & $\sqrt{ }$ & $\sqrt{ }$ & & $\sqrt{ }$ & $\sqrt{ }$ & \\
\hline $\begin{array}{l}\text { Other } \\
\text { control } \\
\text { variables }\end{array}$ & $\sqrt{ }$ & $\sqrt{ }$ & $\sqrt{ }$ & $\sqrt{ }$ & $\sqrt{ }$ & $\sqrt{ }$ & $\sqrt{ }$ & $\sqrt{ }$ & $\sqrt{ }$ \\
\hline SES & $\sqrt{ }$ & $\sqrt{ }$ & $\sqrt{ }$ & $\sqrt{ }$ & $\sqrt{ }$ & $\sqrt{ }$ & $\sqrt{ }$ & $\sqrt{ }$ & $\sqrt{ }$ \\
\hline $\begin{array}{l}\text { Fixed } \\
\text { effects of } \\
\text { origin } \\
\text { provinces }\end{array}$ & $\sqrt{ }$ & $\sqrt{ }$ & $\sqrt{ }$ & $\sqrt{ }$ & $\sqrt{ }$ & $\sqrt{ }$ & $\sqrt{ }$ & $\sqrt{ }$ & $\sqrt{ }$ \\
\hline $\begin{array}{l}\text { Fixed } \\
\text { effects of } \\
\text { flow-in } \\
\text { cities }\end{array}$ & $\sqrt{ }$ & $\sqrt{ }$ & $\sqrt{ }$ & $\sqrt{ }$ & $\sqrt{ }$ & $\sqrt{ }$ & $\sqrt{ }$ & $\sqrt{ }$ & $\sqrt{ }$ \\
\hline$N$ & 7325 & 7325 & 7325 & 6348 & 6348 & 6348 & 1641 & 1641 & 1641 \\
\hline
\end{tabular}

Note: Robust standard errors are reported in parentheses. ${ }^{*} p<0.1,{ }^{*} p<0.05,{ }^{\star \star *} p<0.01$. Other control variables include individual demographic characteristic, self-reported health status, having hypertension or diabetes, fitness time, having health examination or not in the past year. SES includes education, income, expenditure and immigration information. Same structure of dependent variable as in table 2. The columns (1)-(3) have same structure as column (3), (6) and (8) in table 2. The columns (4)-(6) have same structure as column (3), (6) and (8) in table 3. The columns (7)-(9) have same structure as column (3), (6) and (8) in table 4. In this regression, we drop the individuals whose YSM is less than one. 